\title{
1 Responsibility for future generations - scope and limits Dieter Birnbacher
}

\section{Future ethics - a contradiction in terms?}

Responsibility, understood in an ex-ante or prospective way and referring to possibilities of conduct not yet realized, is necessarily futureoriented. Therefore, we are always responsible - in terms of an obligation to concern - for actions or events which, from the subject of responsibility's point of view, take place in the future or at least reach into the future. Thus, responsibility as such means always and necessarily responsibility for the future. If so, why do the terms 'responsibility for the future' and 'responsibility for future generations' require a special classification and accentuation? Under the present circumstances, responsibility for future generations, which in former times was more or less seen as an integral part of the traditional term of responsibility as a whole, has been given a new complexion. In his significant work The Principle of Responsibility Hans Jonas pointed out some of these new circumstances (Jonas 1979): one of them is the potential increased by modern technology to influence men's and nature's future fate by acting or refraining from acting. What once could be taken for fate is now gradually entering the sphere of human control. Another circumstance consists of the growth of possibilities of human foresight and the early detection of dangers and risks. It gets more and more difficult for agents to excuse themselves by claiming ignorance in order to avert uncomfortable situations. Even though the 'world of impacts' and the 'world of perception' still differ enormously and we can barely foresee the consequences of our present acting, the more historical experiences we make, the better backed up ideas we get of chances and risks of our interventions in nature and the human world.

Inevitably, both tendencies lead to an extension of our responsibility. The extended possibilities of interference in distant futures (for example concerning climatic problems) as well as grown possibilities of a farreaching risk calculation (regarding the consequences of climatic upheavals for the agricultural production in developing nations) does not remain without influence on the normative sphere. The knowledge about probable consequences of present acting and refraining from acting forces us - even though we may refuse to accept it - to take over an appropriate future 
responsibility followed by a future ethics. With increasing knowledge power increases as well, but at the same time so does responsibility.

The idea of a future ethics regularly raises various objections. Some critics say that the idea of a 'future ethics' necessarily results in an anonymity of future responsibility in the long term. Responsibility gets vague and unspecific if - without considering the whole complexity of role relations - it is directed at people seen as 'abstract, homogeneous individuals' whom we do not know nor are able to know as they will live in the distant future (Becker 1989, p. 7). Becker states that responsibility cannot be separated from its archetype, the special responsibilities going with social roles in the context of small groups.

Other critics confine themselves to a rejection of a 'future ethics' from a pragmatic point of view and ask who - under real moral-psychological circumstances - could be expected to not only pay lip service to such an ethics but indeed show his or her allegiance to it. According to this opinion, responsibility has to be limited if it is not to be felt as overdemanding. As ethics is not concerned with ideal norms for fictitious agents but with reasonable and practicable norms for real agents, demands for responsibility cannot be extended indefinitely without defeating ethics' true purpose. Does this mean that the process of 'unlimiting responsibility', (Kamlah 1973, p. 105) which started with the Enlightenment and has persisted until now, ought to be annulled? Should the demand for more and widerreaching responsibility be rejected for being far too demanding? Not at all, I think. We need to keep an eye on the limits of responsibility, but at the same time we need to be open to the extension of responsibility resulting from an extended foresight, extended abilities but, above all, from an extended moral goodwill and a willingness to act.

\section{Limits of responsibility}

In some ways, responsibility is already limited by its semantic features and the meaning of the term 'responsibility' itself. The first limit to be mentioned may seem to be trivial at first glance, but is not if we have a closer look at it: when talking about responsibility an agent shall keep to or take upon himself, we normally do not refer to the entirety of moral obligations the particular agent has within a specific object area but, primarily, to the obligations of action he has in this area. Usually, taking over responsibility includes active acting and not merely refraining from acting. Taking over responsibility for somebody normally means doing something in an active sense in order to protect, support and provide for another person.

Summed up, the meaning of this in the first place purely conceptual feature lies in the 'costs' and 'opportunity costs' which are caused by taking over responsibility for a certain subject of responsibility. Taking over as 
well as carrying out obligations of action results in a greater effort and in a limitation of pursuing other interests than taking over and carrying out mere obligations of abstention.

The second limit consists in a restricted ability. Responsibility in terms of its scope and content is connected to objective and subjective power. The decisive objective power factor lies in the fact that it is first of all the situational conditions which make it possible to influence a specific event. The object of responsibility must not yet be removed from a possible source of influence because of objective reasons. It is not important if the subject of responsibility can influence an event directly, substantially or with a high chance of success, but if he or she is kept from influencing an event, no matter how indirect, insignificant or partly successful that influence may be. The decisive subjective factor is the subject's individual ability or inability to make use of the objectively given scope of intervention. Whoever is limited in his scope of conduct, for example because of neurotic constraints, is not as suited for taking over and carrying out responsibility as somebody who is emotionally in complete control. For instance, we are responsible for our own character just to the extent - but so far we are - of being able to influence it by controlling the deliberate choice and the avoidance of potentially formative influences and experiences.

The third limit is the restriction of human foresight. Nobody can be blamed for not having avoided troubles he or she could in no way foresee or expect under the given circumstances. In the field of new technologies it may well occur that some agents are expected to be responsible in order to provide against risks which are neither concretely defined nor backed up with a precise probability. However, in this connection assigning responsibility to somebody can be justified with the consideration that with historical experiences, especially in the field of new technologies with short testing intervals or a high testing risk, at least an abstract, less calculable and hypothetical risk has to be assumed.

Thus, a 'future responsibility', as it is claimed by Hans Jonas and other experts, cannot be regarded as wrong or inept just for conceptual reasons. It is absolutely legitimate to see the prototype of responsibility in the roleattached responsibility within the sphere of social proximity, which does not automatically mean to dogmatize it or limit the scope of responsibility for good. Beside the father's responsibility for his children, the teacher's responsibility for his or her students, the statesman's responsibility for the nation's welfare and so on, it is thoroughly possible to speak of a comprehensive, role-transcending responsibility, such as the foreigner's responsibility for another foreigner, the statesman's responsibility for the international community of nations and present people's responsibility for the future. A 'total responsibility' (Hans Jonas) is not a contradictio in adjecto. 
The assignment of responsibility would only be confronted with conceptual objections if it disregarded essential conditions of a legitimate assignment of responsibility, that is if it was assigned to constructs like 'mankind' or 'the present generation' which cannot be reasonably assumed to be subjects of action, if present individual or collective acting had no kind of significant global or temporal long-distance effects; or if the carriers of future responsibility were not able to influence - in whatever direct form - the alarming developments. None of these conditions of exclusion applies to the responsibility for future generations. If responsibility is assigned to pseudo-subjects like 'man' or 'the present generation', it can normally be interpreted as an elliptical phrase for demands that are primarily directed to those collective agents who have the strongest influence, for instance present governments or leading industrialists in industrial nations. Neither are the other two conditions of exclusion fulfilled. Global and intergenerational long-distance effects of present acting or refraining from acting are not just inventions of ecological fanatics but undisputed reality. The fate of developing nations, the future of the global climate and the continued existence of nature's species depends very much on the leading industrial nations and their financial, economic, agricultural and environmental policies. Even though politically and ecologically involved citizens in those countries might tend to considerably overestimate their own influence on their governments' policies, it would be clearly wrong to deny them any, however indirect, political influence. At least those who hold a key position in politics or administration as well as lobbyists and other representatives of pressure groups, plus the heterogeneous group of academic political consultants, play a decisive role in the matter of longdistance strategies and decisions and thus are responsible for it as well.

\section{Responsibility for the future: the optimistic and the pessimistic paradigm}

Two alarming global developments made responsibility for the future a key concept of political ethics:

1. the continuing though in the meantime slightly reduced exponential growth in population and its foreseeable consequences; and

2. the continuing exponential growth in the human utilization of nature.

The rapidly growing exploitation of nature by men does not only affect nature as a source of natural goods like soil, water, resources and energy, but also as a dump for substances and pollutants from production and consumption like waste, residues, air and water impurities and climate changing greenhouse gases. The excessive utilization of resources and dumping sites forms a major part of the burden that will be passed on to future 
generations. Furthermore, there will be irreversible risks which coming generations will have to adapt to - risks like those that originate from radioactive waste from usage of nuclear energy or climatic risks provoked by the release of carbon dioxide from burning fossil fuels. So far, it is not the growth in population which is to blame in the first place for having produced this burden, but the growth in activities of a small part of the world population that intensified carelessly their exchange processes with nature in production and consumption without even thinking about the natural restrictions of our 'blue planet'. This situation might well change when emerging countries with a high population density like India or China join the club of industrial nations. As early as today, the greatest risks the atmosphere's ozone layer has to fear are not caused by the industrial nations, but by emerging countries rich enough to make use of raw materials but too poor to do without an environmentally hazardous exploitation of nature. Taken as ideal types, one can distinguish between an optimistic and a pessimistic paradigm of future ethics. The optimistic paradigm regards responsibility for future generations primarily as an obligation to prolong a more or less reliable process of progress which starts in present time and will continue in the future. This paradigm, in which future generations are generally better off than present generations, is characteristic of the main currents of the Enlightenment philosophy (Condorcet, Kant), of Marxism (Bloch), of 'neoclassical' economic theory and the liberal political philosophy including Rawls's 'theory of justice'. Regardless of existing differences, the representatives of these schools of thought share the opinion that the future will bring along a process of increasing perfection (Condorcet), increasing prosperity (Rawls, neoclassicism) or decreasing torment of labour (Marx). In contrast to this view, the pessimistic paradigm sees future generations in a potentially worse position than present generations. Responsibility for future generations thus is of a conservative nature and contains primarily the obligation to maintain the status quo, be it of a technological, economic or cultural nature, in order to avert harms, provide for future disasters and to minimize risks. The pessimistic paradigm forms the basis of nineteenth century Malthusianism, of the twentieth century eugenic movement and many specifically ecological future-ethical ideas. The leading affect is the fear of future deteriorations instead of the hope for coming improvements. Within Malthusianism, it is the fear of an unlimited growth in population, within eugenics the fear of a degeneration of the genetic pool, and in many models of ecological economy it is the fear of an endangering of the natural bases of living and thus the fear of endangered conditions for mankind's continuing existence in general. This attitude is reflected in Hans Jonas's postulate of a 'heuristics of fear'. According to this postulate, risks shall be avoided in the first 
place, while opportunities shall be seized only afterwards. Hence, the emphasis is put on the risks of harm instead on the opportunities of success. In case of doubt, people should do even without a possible technological progress for the benefit of minimizing the risk of imminent disasters.

That the distinction between an optimistic and a pessimistic paradigm only works in an ideal-typical way is among other things revealed by the fact that the probably most important implicit 'future ethicists' of the nineteenth century, Marx, Engels and Mill, took the side of both paradigms. The same Marx who hoped for the proletariat's liberation from the 'unleashing of productive forces' with the help of progressive technological control of nature at the same time sensed the 'disparagement' of nature through human exploitation, as well as the dangers of Raubbau, first mentioned by Justus von Liebig:

Any progress of capitalist agriculture is not only a progress in the workers' skills, but at the same time a progress in the skills of exploiting the soil, any progress in increasing its fertility for a given period of time at the same time means a progress in the destruction of the lasting sources of this fertility. The more a country, as for instance the United States of America, thinks of big industry as the foundation of its development, the faster progresses this process of destruction. Capitalist production thus only can develop the technology and the combination of the social production process by undermining simultaneously the sources of all wealth: the earth and the workers. (Marx 1965, p. 529 et seq.)

The same holds true for Engels, for whom the destructive exploitation of natural resources forms one of capitalism's mortal sins. One of his examples still has a remarkable relevance to the present:

The Spanish coffee planters in Cuba who burnt down the woods along the slopes found enough fertilizer in the ashes to manure one generation of extremely profitable coffee trees - what did they have to worry about the tropical rainpours that afterwards would wash off the shelterless earth and leave nothing but bare rocks. (Engels 1973, p. 455)

The optimist in terms of progress, Mill, was not only one of the first persons to politically plead for birth control in public (among other things for the benefit of female emancipation from exclusively domestic tasks) but also for a stagnation of economic growth in order to maintain natural goods while simultaneously continuing cultural and moral development:

If the earth lost the very part of its pleasantness which it now owes to these things that an unlimited accumulation of property and an unlimited growth in population would take away from it just to nourish a numerously grown, but in no way better or happier population, I hope with all my heart for the sake of 
future generations that people will be content with constant conditions much earlier than they will be forced to. (Mill 1869, p. 62 et seq.)

\section{The temporal and ontological scope of responsibility for the future}

All theoretical basic questions in the field of future ethics are at the same time of practical relevance:

1. the question of the temporal scope of responsibility for the future (which period of time?);

2. the question of the ontological scope, of the objects of a responsibility for the future (for whom?);

3. the question of the contents of responsibility for the future (for what?);

4. the question of the significance of responsibility for the future compared with responsibility for the present, and

5. the problem of motivating people to accept and practically take over responsibility for the future.

Regarding the temporal scope of responsibility for the future, most moral philosophers share the opinion that it includes the entire foreseeable future and is limited only by the limits of prognostic knowledge. There is already an implicit connection to the total of future generations within the term irreversibility, which means that any future generation will have to live with certain changes. Animal and plant species that become extinct and non-regenerative raw materials that are exhausted are no longer available for any of the future generations. Theoretically, the consideration of all coming generations does not bring about great problems. As the number of generations living in the future is certainly finite, no 'infinity paradoxies' (like the non-existence of infinite utility integrals) will arise for a mathematical calculation. Still, there are a few moral philosophers who have normative doubts and thus deny the fact that we could be obliged to provide for more than the following two generations, as we will only get to know representatives of directly subsequent generations. (In contrast to the rather universalistic tendency of his ideas of justice, John Rawls supports this strict limitation of responsibility for the future in his 'theory of justice'.) The problem with these ideas is to explain why, on the one hand, intergenerational moral responsibility should be bound to face-to-face-contacts or spontaneous emotions of liking, while on the other hand moral obligations for affected abstract (or statistical) people do well exist, as for instance in the case of avoiding risks while we do not know ex ante the probable victims that might be affected by them. One of the essential social functions of moral obligations is to replace personal obliging relations and to extend the horizon of responsibility 
beyond the narrow circle of emotional proximity. The guiding principle of a parent's responsibilty (Jonas and Passmore) must not be interpreted too narrowly. Many of the present damages to the environment (for example the global warming because of the emission of greenhouse gases) may effect not our generation but our great grandchildren's, which does not lessen in any way the present generation's responsibility to avoid such damages. That loving one's neighbour in the literal sense of exclusive solidarity with one's neighbours does not form a solid base for futureethical norms has already been indicated by Nietzsche's polemic expression of the necessity of a 'Fernstenliebe' - a solidarity with those most far away.

There is considerably less consensus regarding the question for who responsibility shall be taken over. Anthropocentric concepts postulate that an obligation to provide for the future exclusively applies to the future descendants of mankind. An obligation to preserve nature and its subsystems (ecosystems, biotopes, species) exists only so far as it could be of use for future human generations, be it as a resource for a practicaltechnological purpose (instrumental value) or be it as an object of a contemplative (theoretical, religious or aesthetic) attitude (inherent value). As far as an explanation for this position is even considered (bearing in mind the traditional predominance of the humanist-anthropocentric point of view), it usually refers to the exceptional position of man as an intellectual being, a functional being (Jonas) or - in the Kantian tradition - a rational or moral being. By contrast, pathocentric concepts add animals with the capacity of sentience to the circle of morally significant beings, but in a restricted way through demanding only measures that aim at the avoidance of harm for the animals but not stating a right to exist for them. Biocentric concepts go far beyond this restriction by not only granting individual animals and plants a right to exist (as does Taylor 1986) but also generation-transcending ecosystems and biological species. From this point of view, the present generation is directly obligated to maintain the integrity of natural systems and species in the long term and irrespective of their practical use for men. However, in the case of conflict, restrictions in favour of men are made (though not by strict generic egalitarians like Taylor, for instance). Even irreversible losses of an ecosystem or a biological species shall be accepted if prohibitive costs or opportunity costs (costs of not using a resource) arise for men.

In spite of differences of opinion in basic principles, future-centred moral philosophers agree on numerous concrete evaluations, for example when diagnosing the danger of the present rapid extinction of biological species, or when demanding the protection of the most vulnerable natural cycles (for example the tropical rain forest) against human intervention. 


\section{The contents of future responsibility}

The definition of the content of responsibility for future generations reflects the whole variety of normative opinions held in philosophical ethics today. In order to structure the variety of approaches (I only consider the anthropocentric ones) they will be divided into separate dimensions.

\section{Provide exclusively for the well-being of people existing in the future or also provide for their existence?}

An extreme position is taken by Patzig (1983, p. 16 et seq.) who answers this question as follows: 'We are only obliged to provide for the satisfaction of needs of those members of future generations who will live anyway, we are not obliged to safeguard the survival of mankind.' Of course it would be undoubtedly regrettable if mankind became sterile, but as long as nobody is harmed, it would not be morally questionable. (A similar answer would be given by average utility utilitarianism). The extreme answer on the opposite side is postulated by several Catholic moral theologians, who claim that mankind, irrespective of possible conditions that might not allow a life worth living, is obliged to reproduce. Between these extreme positions lies the answer of total utility utilitarianism and of analogous non-utilitarian theories. The important issue for these theories is not mankind's survival at whatever cost, but enabling all generations to achieve the highest sum of welfare. As long as people regard life as worth living, the continued existence of men (respectively the existence of conscious life) on earth is a high value. The disappearance of conscious life would be a moral disaster, even if it came in a subtle way and did not bring about additional harm. Therefore, a similarly important role has to be assigned to the sustained preservation of resources needed for human survival.

\section{Want-regarding axiology versus ideal-regarding axiology}

According to an exclusively want-regarding axiology, we are obliged only to make provisions for the (probable) needs of future generations. If we were convinced that the members of future generations had no direct or indirect interest - in whatever form - in biological species that are becoming extinct today, we would not be obliged (or not even entitled) to do anything in order to preserve those species. In contrast, an ideal-regarding axiology as, for example postulated by Hans Jonas demands provisions beyond that and requires a continued development and cultural enrichment of human preferences. At least there should not be a lowering of these preferences to an inferior level. This theory does not only aim at securing the (in each case subjectively judged) quality of life, but at securing the quality of men themselves.

Personally, I defend the priority of the want-regarding axiology over the ideal-regarding axiology, and I understand it in a quite strict and literal way 
(Birnbacher 1982). As I see it, this priority can be explained with the substantially higher universalizability of the value of satisfaction of needs or preferences. While values like virtue, dignity, justice, harmony and beauty can be discussed extensively and have been discussed extensively, the assumption that those things that a subject itself - irrespective of the consequences - perceives as something positive and satisfying at the same time is something positive objectively is a common axiom of any axiology ever seriously proposed. The condition of universalizability is part of the very structure of moral responsibility, in virtue of the fact that moral responsibility is not only assigned to a person him- or herself but also to other persons. It is only possible to expect somebody else to take over the responsibility assigned to him or her if he or she is given reasons that can be understood and accepted.

It won't be possible to refer to axiological assumptions that can only be justified by quoting authorities such as positive law, popular tradition or religious authorities. One can only expect somebody else to accept the responsibility assigned to him or her if taking over and carrying out this responsibility results in the realization of a value that can be assumed to be accepted by anybody.

\section{Intergenerational maximization versus future ethical minimalism}

The concepts of intergenerational justice currently discussed differ in the extent to which the present generation is expected to make provisions for future generations. The most demanding requirement is made by utilitarianism, which requires an economical use of resources whenever the welfare of future generations can be increased in a degree exceeding the expenditure made in the present. As long as today's investments for tomorrow and the day after tomorrow promise a higher profit than the asset we lose by making those investments, we are obliged to invest.

The utilitarian model leads to a distribution of welfare that is extremely unequal over generations. Under realistic circumstances, the poorest generations (for example 'rebuilding generations' after crises like war) would have to economize a lot in order to make investments for future generations. If we assume circumstances characterized by inexhaustible resources, even the richest generations would no longer be obliged to economize as they would not be able to improve the situation of coming generations. This is the case when the marginal utility of an additional income has become so small that it cannot compensate for the investments.

The most common criticism when it comes to utilitarian models of intergenerational justice focuses on the expectation that former generations should make sacrifices in order to improve the welfare of future generations, even though it can be assumed that future generations (for example 
because of technological progress) will be on a much higher level: doesn't this mean an intolerable unfairness of intergenerational distribution, a grave disproportion between cost and benefit? In practice, this undeniable unfairness could be reduced by making sure that obligations of provision of former generations do not exceed defined limits of reasonableness. Only in this way can they be accepted and complied with by former generations. The ideal scenario is not automatically the one we are morally obliged to realize. Thus, we cannot demand of today's poorest countries, which already have enough own problems of provision, to considerably economize for a future, more populous generation.

A pessimistic scenario, according to which the future will not be better but worse off, makes the consequences of utilitarian obligations of provision intuitively much more acceptable. From a pessimistic point of view, the sacrifices made by former generations do not serve to improve the welfare of future generations, which is anyway acceptable, but to avoid disasters.

The opposite extreme are minimalistic solutions of the intergenerational distribution problem that oblige the current generations to preserve the stock of resources inherited from the preceding generation but do not expect them to make any further provisions. Since the United Nations' Brundtland Report has become an integrative political key term, the principle of sustainable development occasionally has been interpreted in this minimalistic sense. According to the report, in a world of limited resources each country should have the right to develop its economy as long as the total stock of global resources is not reduced. Similar to John Locke's theory of property according to which an original acquisition of land is justified to the extent that 'enough, and as good' will remain for other people (Locke 1924, p. 130), each generation should use the available resources in a way that there will still remain enough resources of the same quantity and quality for the next generation.

As we know from experience, it is by no means easy, politically, to secure even this minimum standard of sustainability. From an ethical point of view, however, this standard is far too minimalistic and clearly insufficient. First, it does not consider the foreseeable - and in the short term unavoidable - global growth in population. If the next generation has at its disposal the same stock of resources as the present generation, but a population that is about 50 per cent larger (and the following generation twice as large), keeping to the minimalistic strategy results in a higher risk of disaster for the members of the next generations. That is why Gregory Kavka (1978) suggested rephrasing the Lockean Standard in a way that not the generations but the members of the generations should have the same resources. Under given circumstances, this standard claims considerably higher provisions than the minimalistic standard does. 
Another critical issue is that the sustainability model completely disregards the initial level from which a policy of conservation starts. Thus, nations like Japan or the Netherlands achieve remarkable scores on the sustainability scale developed by Pearce and Atkinson only because the initial level of natural capital in both nations has been quite low from the beginning. The sustainability scale does not consider the total amount of natural capital nor the destruction of natural capital before the measured period (Scherhorn and Wilts 2001, p. 252).

Furthermore, the minimalistic model allows to refrain from improving the future generations' situation even when relatively great improvements of welfare for coming generations can be achieved by relatively small investments and sacrifices by former generations. This will sometimes be the case if technological progress allows future generations to make use of available resources in a much more effective way than the present generation, so that future generations might regard the present use of limited resources as a huge waste, for instance the use of mineral oil as fuel instead of as a chemical raw material.

A similar minimalistic model follows from an intergenerational application of Rawls's Difference Principle originally proposed for intragenerational distributions (Birnbacher 1977). Under the optimistic assumption of inexhaustible resources, constant population and an autonomous technological progress (independent of capital accumulation), this principle even allows a previous generation to leave less to the following generation than it inherited since it can rely on the fact that the following generation, thanks to technological progress, will be able to achieve the same level of welfare using less resources. Since each generation expects the following generation to be better off, tremendous possibilities of development will remain unused. The complete sequence of generations remains on the level of hunter-gatherers - a consequence that made Rawls change his intragenerational principles for the problem of intergenerational justice.

\section{Discounting the future and the problem of motivation}

Another controversial issue is the importance of obligations towards future generations in relation to the importance assigned to present generations. While utilitarianism as well as the Kantian tradition tend to see future and present responsibility as equivalent, numerous economic models adapt to the widespread psychological tendency to devalue future utility ('time preference') and to 'discount' future benefit and harm relative to present benefit and harm by treating them like a monetary factor which in a dynamic national economy gradually loses value the more it shifts into the future. The higher the supposed 'social discount rate', the less importance is 
assigned to any future benefit and harm produced by present day behaviour and thereby to the obligations towards future generations.

Discounting monetary values and disvalues - and values commensurate with money - is justified whenever in the respective national economy a real interest rate can be expected that turns an amount saved today into a higher real future amount and thus, from a present point of view, devaluates future returns of the same amount as present returns. (This idea justifies 'discounting' but limits it at the same time.) However, this does not result in a corresponding devaluation of future benefit or harm unless discounting is justified by uncertainty, which can be expected to increase with futurity. As a statement of moral psychology it may be true that 'aware of the fact that he would lose his small finger tomorrow, [. . . ] he would not get to sleep tonight; but if a million of his brothers died he would snore in the deepest peace of mind - provided that he had never seen them before' (Smith 1977, p. 202). But the same Adam Smith who made this statement as a moral psychologist insisted as a moral philosopher on the fact that this subjectively distorted perspective should be replaced for ethical purposes by the impartial and universal view of the 'ideal observer'. Morality is not merely a reduplication of affective relationships but their functional substitute. Richard Hare (1981, p. 100 et seq.) even was of the opinion that privileging the presence or the near future by 'discounting' future values is incompatible with the essential meta-ethical principle of universalizability which claims that facts identical in all relevant features should be judged in the same way. The mere temporal position of two facts (from the point of view of a currently deciding person) is, according to Hare, no feature that would allow different judgements. However, Hare seems to overlook that a differentiation of responsibility for future generations can be expressed by using relational terms expressing relative temporal distance. The principle of universalizability is perfectly compatible with postulating more farreaching moral obligations towards the generation of one's children than towards the generation of one's grandchildren and the generation of one's great-grandchildren.

If an objection can be raised against the practice of discounting future benefit and harm it is not by appealing to the principle of universalizability of moral and morally relevant judgements but by appealing to the principle of the impartiality of the moral point of view. Only judgements that are made from an impartial moral point of view have the chance to be candidates for the claim to universal validity characteristic of moral judgements. Once this point of view is taken, the question arises how privileging the present or the near future can be justified. Preferring what is present over what is future means to be heavily biased. Such a bias could not be justified by moral but merely by pragmatic considerations, that is by 
considerations of the degree of conformity to be expected for future ethical norms, especially if these are felt to make excessive demands (Birnbacher 2003, p. 47 et seq.).

The question of moral pragmatics naturally leads to the problem of motivation connected with the issue of responsibility towards future generations. This problem arises from two sources: the temporal impartiality of responsibility claimed by almost all varieties of universalist ethics, and the causal asymmetry between present moral agents and future moral patients. We are able to harm future people, but they are not able to reciprocate. In contrast to intragenerational decisions, selfishness (neglecting other people in one's own favour), moral distance (neglecting foreigners in favour of friends), and time preference (the neglect of the future in favour of the present) remain without sanctions in intergenerational decisions. A selfish and myopic agent has no reason to make provisions for future people. An agent who is selfish but not myopic has at most a reason to make provisions to the extent that he wishes to be positively remembered by his descendants.

In comparison to human selfishness, which traditionally is a central topic of ethical anthropology, time preference and the tendency to be 'oblivious of the future' have been rarely discussed in philosophy. It was discussed explicitly by Spinoza, who thinks of it as a case of irrationality which should be corrected by sound reason, as well as by Hume and Bentham, who speaks of 'propinquity and remoteness' as one of the 'circumstances' on which the appropriate judgement on pleasure or pain depends (Birnbacher 1988, p. 87 and p. 197). Within economics, the phenomenon of time preference was best analysed by the Austrian capital theorist Eugen von Böhm-Bawerk who distinguished three motives because of which present consumption is preferred to future consumption:

1. pure (positive) time preference, the preference of the present merely because of it being present;

2. the expectation of a decreasing marginal utility because of increasing possibilities of consumption in the future; and

3. the chance to realize technological progress through present consumption which increases future possibilities of consumption (BöhmBawerk 1889, p. 262 et seq.).

A fact that complicates the practice of taking over future responsibility is the anonymity of future generations and the uncertainties of prognostic knowledge. Both facts make it easier for us to psychologically suppress recognized future dangers and to underestimate them in comparison to present dangers. The tendency to feel responsible for merely statistical 
victims is much less pronounced than the tendency to feel responsible for known victims. The tendency to avoid certain future harm or to seize certain future benefits is far more pronounced than the tendency to avoid risks or to forgo chances. How is it possible to cultivate the motivation for a future ethic? In this context, concepts become relevant that are especially focused on in communitarian theories within social philosophy (de-Shalit 1995). It is important to develop a consciousness of one's own temporal position in the sequence of generations as well as a generationtranscending sense of community, if not with humanity as a whole, then with limited cultural, national or regional groups. The aim should be to develop gratitude towards past generations and to take over obligations for future generations at the same time. In order to correct distortions in the judgement of natural and cultural resources due to short-sightedness and selfishness, the model of a hypothetical future market might be useful on which future generations express their demands in addition to the present generation. (This model corresponds to the intergenerational variation of Rawls's original position.) The price non-regenerative resources would fetch on such a future market would be a better benchmark for the 'real value' than actual market prices, which insufficiently consider the shortage of natural resources.

In all probability, a changed consciousness will not do to make political decisions focus more on natural resources and their future usage instead of exclusively considering market prices (see the chapters in the third part of this volume). An additional step would be the representation of the (probable) needs and interests of future generations in present decisions, for example by appointing spokespeople for future generations on a local, regional, national and international level. Furthermore, the legal institution of a Verbandsklage (group action) could be extended beyond the issues of nature to the issues of future generations. In this way, the 'future compatibility' of government action could be monitored. For controlling and sanctioning national policies that disregard the future a global court of justice (Weiss 1989, p. 121) would be an additional option. Even a commission comparable to the UN's Human Rights Commission without sanctioning powers would be helpful, merely being able to make public and to denounce violations of the interests of future generations such as the clearing of rainforests, desertification and the emission of greenhouse gases.

\section{Bibliography}

Becker, Werner (1989), 'Der fernethische Illusionismus und die Realität', in Salamun, Kurt (ed.), Aufklärungsperspektiven, Tübingen: J.C.B. Mohr, pp. 3-8.

Birnbacher, Dieter (1977), 'Rawls' Theorie der Gerechtigkeit und das Problem der Gerechtigkeit zwischen den Generationen', in Zeitschrift für philosophische Forschung, 31, 385-401. 
Birnbacher, Dieter (1982), 'A priority rule for environmental ethics', in Environmental Ethics, 4, 3-16.

Birnbacher, Dieter (1988), Verantwortung für zukünftige Generationen, Stuttgart: Reclam.

Birnbacher, Dieter (2003), 'Can discounting be justified?', International Journal on Sustainable Development, 6, 42-51.

Böhm-Bawerk, Eugen von (1889), Positive Theorie des Kapitals, Innsbruck: Wagner, 1909-1914.

De-Shalit, Avner (1995), Why Posterity Matters. Environmental Policies and Future Generations, London/New York: Routledge.

Engels, Friedrich (1973), 'Dialektik der Natur', in Marx, Karl and Engels, Friedrich, Werke, Bd. 20. Berlin (DDR), pp. 307-570.

Hare, Richard M. (1981), Moral Thinking. Its Levels, Method and Point, Oxford: Oxford University Press.

Hauff, Volker (ed.) (1987), Unsere gemeinsame Zukunft. Der Brundtland-Bericht der Weltkommission für Umwelt und Entwicklung, Greven: Eggenkamp.

Jonas, Hans (1979), Das Prinzip Verantwortung. Versuch einer Ethik für die technologische Zivilisation, Frankfurt am Main: Jusel.

Kamlah, Wilhelm (1973), Philosophische Anthropologie. Sprachliche Grundlegung und Ethik, Mannheim: Bibliographisches Institut.

Kavka, Gregory S. (1978), 'The futurity problem', in R.I. Sikora and Brian Barry (eds), Obligations to future generations, Philadelphia: White Horse Press, pp. 186-203. Also in Partridge, E. (ed.) (1980), Responsibilities to Future Generations, Buffalo NY: Prometheus Books, pp. 109-22.

Locke, John (1924), Two Treatises of Civil Government, London: J.M. Dent \& Sons.

Marx, Karl (1965), Das Kapital, Kritik der politischen Ökonomie, 1. Band. Berlin (DDR): Dietz.

Mill, John Stuart (1865), Principles of Political Economy, Books 3-5, Collected Works vol. III, Toronto: University of Toronto Press.

Passmore, John (1980), Man's Responsibility for Nature. Ecological Problems and Western Traditions, London: Duckworth.

Patzig, Günther (1983), Ökologische Ethik - innerhalb der Grenzen der bloßen Vernunft, Göttingen: Vandenhoeck \& Ruprecht.

Rawls, John (1975), Eine Theorie der Gerechtigkeit, Frankfurt am Main: Suhrkamp.

Scherhorn, Gerhard and Wilts, C. Henning (2001), 'Schwach nachhaltig wird die Erde zerstört', GAIA , 10, 249-255.

Smith, Adam (1977), Theorie der ethischen Gefühle, Hamburg: Meiner.

Taylor, Paul W. (1986), Respect for Nature. A Theory of Environmental Ethics, Princeton, NJ: Princeton University Press.

Weiss, Edith Brown (1989), In Fairness to Future Generations: International Law, Common Patrimony, and Intergenerational Equity, Tokio/Dobbsferry, NY: Transnational Publisher. 